\section{Caracterização da rede hidrográfica na Estação Ecológica Serra Ge- ral do Tocantins, estados do Tocantins e Bahia}

\begin{abstract}
Resumo: O trabalho consiste na caracterização da Rede Hidrográfica da Estação Ecológica Serra Geral do Tocantins (EESGT) e entorno, localizada entre os Estados do Tocantins e da Bahia, região do Jalapão. Como procedimento metodológico utilizou-se o Geoprocessamento com a organização de um banco de dados via Sistema de Informação Geográfica (SIG) utilizando o software Sistema de Processamento de Informações Georreferenciadas (SPRING). Entre os materiais utilizados estão as Cartas Topográficas, imagens de satélite (Cbers e Landsat), mapas e arquivos digitais. Também foram realizados trabalhos de campo com uso de receptores do Sistema de Posicionamento Global (GPS). O estudo apresenta informações sobre a rede de drenagem, bem como de alguns parâmetros morfométricos da EESGT, entre estes estão: hierarquia fluvial, direção da rede de drenagem, magnitude total, comprimento total, densidade e padrões de drenagem. Os resultados demonstram a importância da EESGT como elemento fundamental na preservação dos recursos hídricos (regionais e nacionais) e do Cerrado como um todo.
\end{abstract}

\section{Characterization of the hydrographic network of the Ecological Sta- tion Serra Geral of Tocantins, Tocantins and Bahia states}

\begin{abstract}
The research is to characterize the hydrography around the Ecological Station Serra Geral do Tocantins (EESGT), located between the of Tocantins and Bahia states in region of the Jalapão. As a methodological procedure used the GIS to the organization of a database using the Georeferenced Information Processing System (SPRING) software. Among the materials used are the topographical letters, satellite imagery (Landsat and CBERS), maps and digital files. Fieldwork with the use of receivers of the Global Positioning System were also conducted. The study presents information on the drainage network, as well as some morphometric parameters of EESGT, among these are: fluvial hierarchy, direction of the drainage network, the total magnitude, total length, density, and drainage patterns. The results demonstrate the importance of EESGT as a fundamental element in the preservation of water resources (regional and national) and the Cerrado.
\end{abstract}

Sandro Sidnei Vargas de

Cristo*

Luis Eduardo de Souza

Robaina**

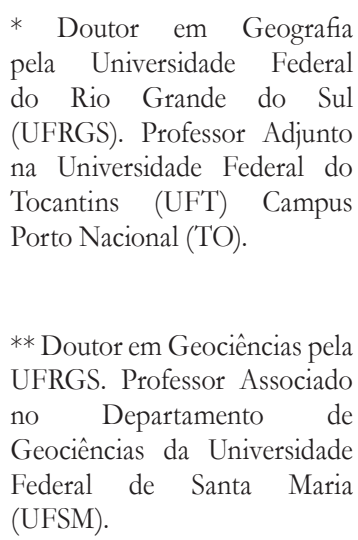

** Doutor em Geociências pela UFRGS. Professor Associado no Departamento de Geociências da Universidade Federal de Santa Maria (UFSM).

\section{Palavras-chave:}

Rede hidrográfica; analise morfométrica; Unidades de Conservação da Natureza

\section{Key-Words:}

Hydrographic network; morphometric analysis; Units of Conservation of Nature. 


\section{Introdução}

As Unidades de Conservação da Natureza (UC) demonstram, cada vez mais, sua importância na preservação ambiental, fazendo aumentar o interesse de pesquisas nessas áreas.

A rede hidrográfica de uma UC é um elemento primordial na manutenção da biota e na definição de processos responsáveis pela esculturação do relevo. Assim, os estudos de caracterização da rede hidrográfica foram desenvolvidos na Estação Ecológica Serra Geral do Tocantins (EESGT). Essa área representa uma importante parcela do Bioma Cerrado e da região conhecida como Jalapão, que abrigam segundo Myers et al, 2000, as últimas grandes extensões da única área de savana considerada como um hotspot ${ }^{1}$ global de biodiversidade.

Segundo Junior \& Rossete (2005) nos estudos de bacia hidrográfica, a mensuração e a análise matemática da configuração da superfície terrestre, quanto à forma e às dimensões de sua paisagem, são usadas nas estimativas das suas características. (morfometria).

De acordo com Milani \& Canali (2000) a aplicação da análise morfométrica facilita a compreensão de forma integrada dos processos hidrogeomorfológicos que ocorrem numa bacia hidrográfica, mesmo quando a sua estruturação é complexa, pois, a partir de uma análise global, pode-se setorizar os seus elementos e identificar à participação isolada de cada um.

A EESGT é uma UC integrante do Sistema Nacional de Unidades de Conservação - SNUC (Lei no. 9.985 de 18/07/2000), criado pela Lei no .42 .009 de 12 de dezembro de 2002. Sendo criada pelo Decreto Federal de 27 de setembro de 2001, com objetivo de proteger e preservar amostras dos ecossistemas de Cerrado, bem como propiciar o desenvolvimento de pesquisas científicas.

A UC está localizada entre as coordenadas $10^{\circ} 25^{\prime} 31,08^{\prime \prime}$ e $11^{\circ} 21^{\prime} 14,33^{\prime \prime}$ de latitude sul e,

${ }^{1}$ Hotspot: Toda área prioritária para conservação, isto é de biodiversidade e ameaçada no mais alto grau (Myers et al, 2000) 47 13 '30,94" e 45 50'32,72" de longitude oeste, na região sudeste do Estado do Tocantins, abrangendo os municípios de Mateiros, Ponte Alta do Tocantins, Almas e Rio da Conceição, com uma pequena parte no extremo oeste do Estado da Bahia que integra o município de Formosa do Rio Preto, apresentando uma área de aproximadamente 707.144ha, sendo que cerca de 631.598ha ficam no Estado do Tocantins e de 75.545ha ficam no Estado da Bahia. (Figura 1)

\section{Procedimentos técnicos e metodológicos}

O levantamento de material bibliográficos e cartográficos foram realizados junto aos órgãos como Secretaria de Planejamento e Meio Ambiente do Estado do Tocantins (SEPLAN), Instituto Natureza do Tocantins (NATURATINS), Instituto Brasileiro de Geografia e Estatística (IBGE), Diretoria do Serviço Geográfico do Ministério do Exército (DSG), Companhia de Pesquisa de Recursos Minerais (CPRM), Instituto Nacional de Pesquisas Espaciais (INPE) e Instituto Chico Mendes de Conservação da Biodiversidade (ICMBio), entre outros com abrangência da área de pesquisa.

Como base cartográfica foram utilizadas as cartas topográficas elaboradas pela DSG e pelo IBGE, todas na escala 1:100.000.

As imagens de satélites foram fornecidas pela SEPLAN (Diretoria de Zoneamento Ecoló-

Geografia Ensino \& Pesquisa, v. 18, n.3, p. 103-116, set./dez. 2014.

Caracterização da rede hidrográfica na Estação Ecológica Serra Geral do Tocantins, Estados do Tocantins e Bahia gico Econômico). Sendo um mosaico de imagens do sensor CCD do satélite CBERS 2, obtidas no período de junho a setembro de 2005, resolução espacial de 20 metros, bandas espectrais 2, 3 e 4, órbitas ponto 158/112 - 157/112 - 156/112 - 157/113 e dois mosaicos de imagens do sensor TM do satélite LANDSAT 5, resolução espacial de $30 \mathrm{~m}$, o primeiro com imagens obtidas em agosto de 2009 e outro de setembro de 2010, bandas espectrais 3, 4 e 5, órbitas ponto 221/67 - 221/68 $-220 / 67-220 / 68$. 
Figura 1-Localização da Estação Ecológica Serra Geral do Tocantins

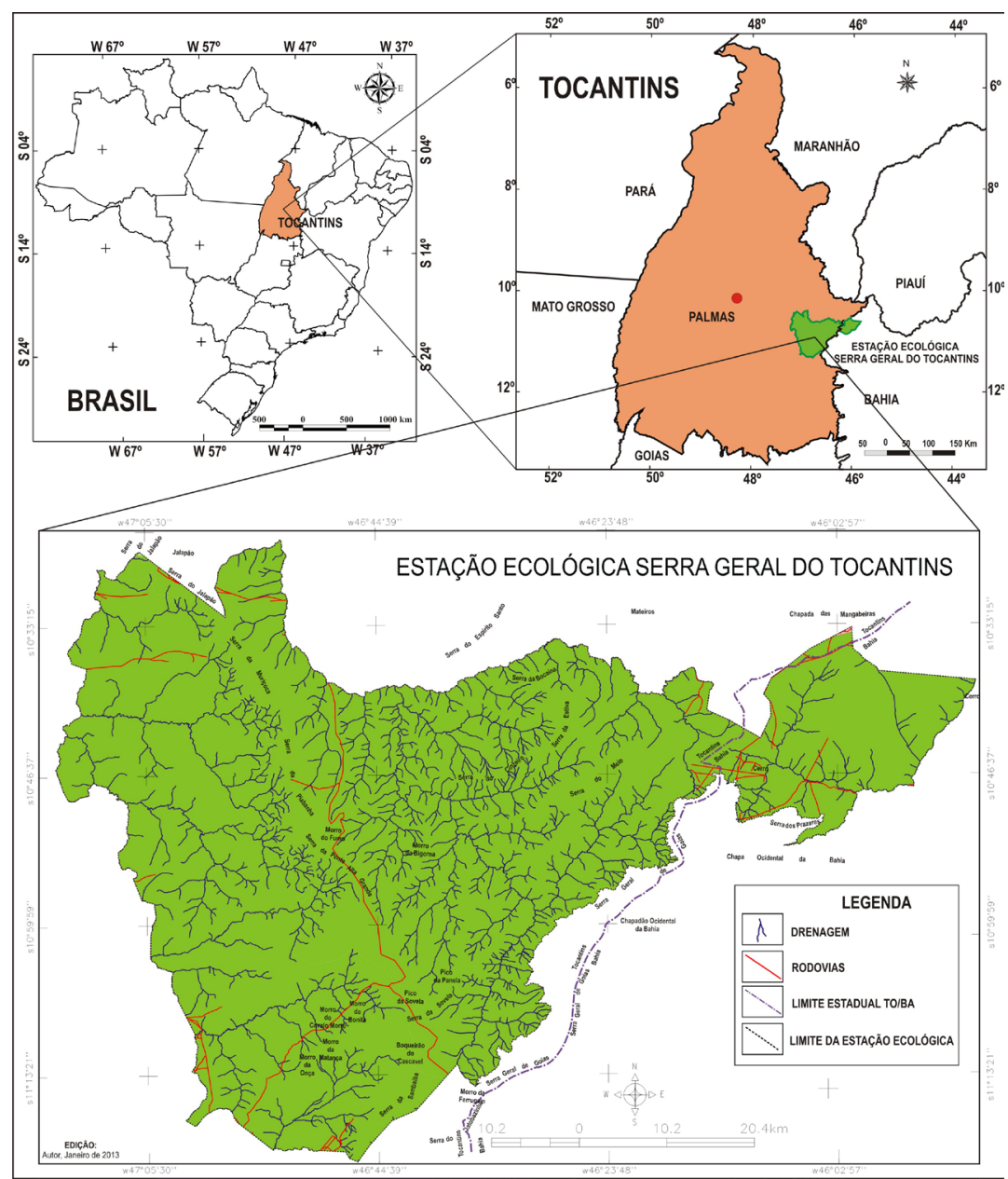

Fonte: Elaborado pelos autores.

Os trabalhos de campo foram realizados através de perfis por caminhos e estradas da região com uso de equipamento de GPS (system of the position global) com levantamento fotográfico dos aspectos físicos para caracterização temática e aferição das informações obtidas nos mapeamentos.

Para a confecção do mapa hidrográfico utilizou-se o software Spring tendo como base o mapa planialtimétrico com escala 1:100.000, de onde retirou-se a rede de drenagem que foi complementada com a utilização de imagens de satélite Landsat 5 do ano de 2010, com resolução de $30 \mathrm{~m}$ da SEPLAN.

$\mathrm{Na}$ definição das características morfométricas da rede de drenagem e das sub-bacias hidrográficas utilizou-se diversos parâmetros como: hierarquia fluvial, direção da rede de drenagem, magnitude total, comprimento total, densidade e padrões de drenagem. Estes parâmetros foram analisados conforme a descrição metodológica seguinte.

A hierarquia fluvial da rede de drenagem foi estabelecida seguindo-se a proposta de Strahler (1952, apud Christofoletti, 1980), foi realizada sobre o mapa Hidrográfico da área de pesquisa.

A magnitude da rede de drenagem foi baseada na ordenação de canais segundo Strahler (1952 apud Christofoletti, 1974) e Scheidegger (1970 apud Christofoletti, 1974), que indica o número de nascentes ou canais de primeira ordem existentes nas bacias hidrográficas, observados sobre o Mapa Hidrográfico.

Segundo Horton (1945 apud Christofoletti,1974) a Densidade de Drenagem é um parâ-

Geografia Ensino \& Pesquisa, v. 18, n.3, p. 103-116, set./dez. 2014.

Cristo, S. S. V. de; Robaina, L. E. de S. 
metro que relaciona o comprimento total dos canais de escoamento com a área total da bacia hidrográfica.

Assim fez-se a aplicação da formula Dd = Lt/A, em que: Dd - é a densidade de drenagem; Lt - o comprimento total dos canais e A - a área total da sub bacia hidrográfica.

A definição dos padrões de drenagem foi realizada com base na metodologia de Strahler (1959 apud Christofoletti, 1974), uma vez que a definição do arranjo espacial dos cursos fluviais indicou uma série de características sobre a resistência do substrato e o controle litológico, bem como das diferenças de declividade e feições do relevo local.

As feições, da rede hidrográfica, como cachoeiras, corredeiras, veredas e lagoas são descritas através de observações em campo.

\section{Análise da hidrografia da área de pesquisa}

A área de pesquisa encontra-se inserida no divisor de águas de duas importantes bacias hidrográficas brasileiras: as bacias dos Rios Tocantins-Araguaia e São Francisco.

A bacia hidrográfica do Rio Tocantins-Araguaia é a principal da EESGT, pois grande parte de suas delimitações, cerca de 1.021,104ha (82,5\% da área total), escoam suas águas para o Rio Tocantins, drenando as porções norte, sul e oeste, onde se encontram parcialmente os municípios do Estado do Tocantins. A bacia hidrográfica do Rio São Francisco abrange cerca de 216.607ha $(17,5 \%$ da área total) drenando a porção leste onde estão as delimitações parciais do município de Formosa do Rio Preto no Estado da Bahia.

Essa característica mostra a importância da EESGT como elemento fundamental na preservação dos recursos hídricos regionais, pois proporciona a proteção de nascentes de importantes cursos de águas.

Os rios que compõem as duas grandes bacias hidrográficas (Rios Tocantins-Araguaia e São Francisco) são constituídas por quatro bacias hidrográficas menores com grande influencia no escoamento regional, que são: as bacias hidrográficas dos Rios Sono, das Balsas e Manoel Alves (integram a bacia hidrográfica do Rio Tocantins-Araguaia) e do Rio Preto (integra a Bacia Hidrográfica do Rio São Francisco) (Figura 2).

A bacia hidrográfica do Rio Sono, têm suas nascentes junto a Serra Geral de Goiás e a Chapada das Mangabeiras, abrange uma área de cerca de 580.430ha drenando quase que a metade da área de pesquisa $(46,9 \%)$ e com duas sub-bacias hidrográficas principais a do rio Novo e rio Vermelho.

A bacia hidrográfica do Rio das Balsas, é composta pelas sub-bacias dos Rios Ponte Alta e das Balsas, com nascentes junto as Serras da Piabanha e da Ponte Alta Grande, local conhecido como Serra da Muriçoca, abrange uma área de cerca de 332.406ha, drena uma boa parcela da área de pesquisa $(26,8 \%)$ distribuindo-se nas porções oeste e sudoeste.

A bacia hidrográfica do Rio Preto, composta pelas sub-bacias dos Rios do Santo e Sapão,

Geografia Ensino \& Pesquisa, v. 18, n.3, p. 103-116, set./dez. 2014.

Caracterização da rede hidrográfica na Estação Ecológica Serra Geral do Tocantins, Estados do Tocantins e Bahia que tem suas nascentes junto a Serra Geral de Goiás e a Chapada das Mangabeiras, abrange uma área de cerca de 216.607ha, drenando uma parte significativa da área de pesquisa $(17,5 \%)$.

A bacia hidrográfica do Rio Manoel Alves da Natividade, a qual tem como principais afluentes o Córrego Grande e o próprio Rio Manoel Alves da Natividade, tem suas nascentes junto as Serras da Sambaíba e do Jatobazinho que integram a Serra Geral de Goiás, abrange uma área de cerca de $87.724 \mathrm{ha}$, drena uma pequena parte da área de pesquisa $(8,8 \%)$, distribuindo-se praticamente na porção sul. 
Figura 2-Bacias Hidrográficas elementares que abrangem a área de pesquisa.

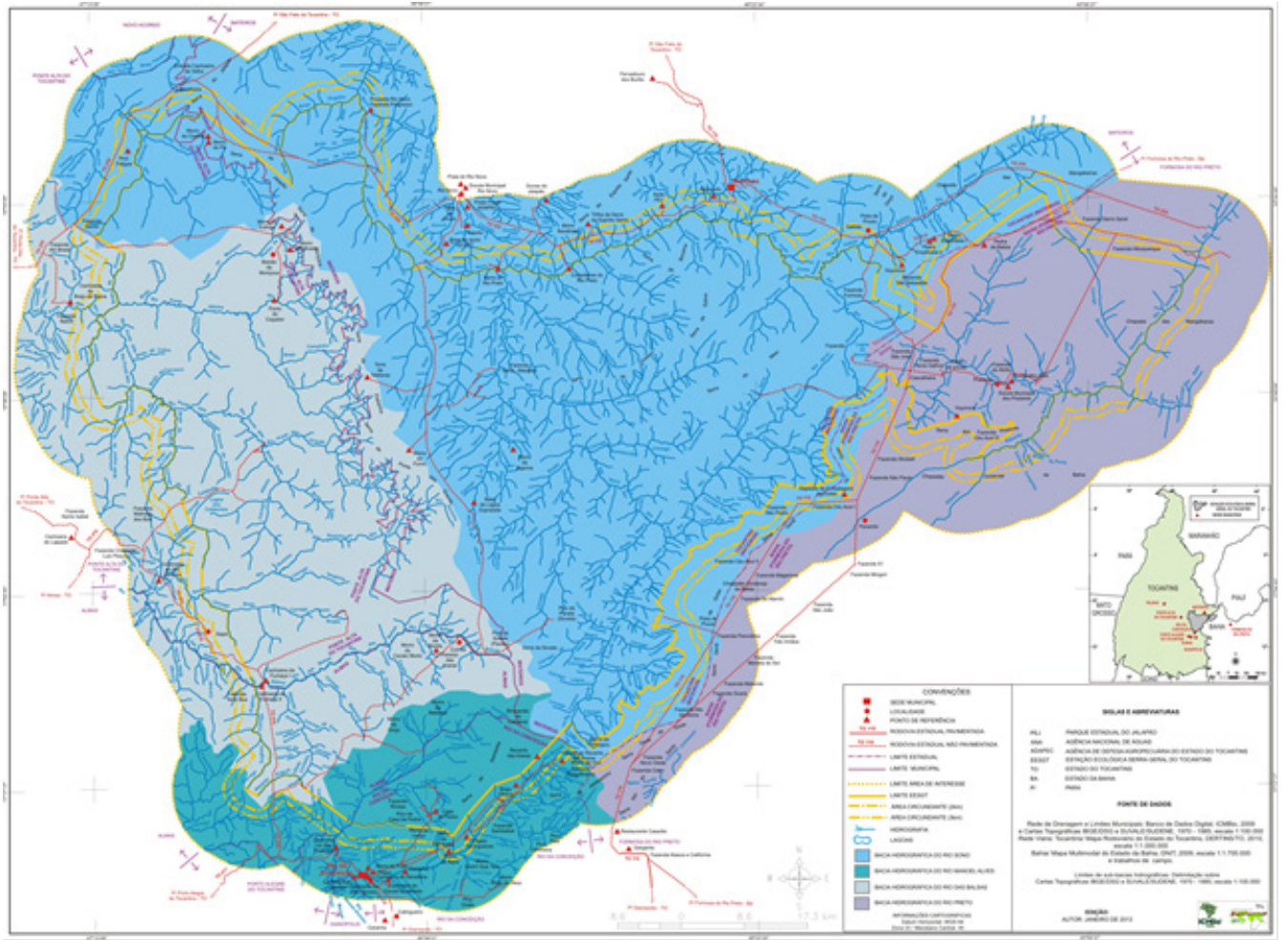

Fonte: elaborado pelos autores.

\section{Analise morfométrica das sub-bacias hidrográficas da área de pesquisa}

A ordenação dos canais fluviais é o primeiro passo para a realização da análise morfométrica de bacias hidrográficas (análise areal, linear e hipsométrica) (CUNHA \& GUERRA, 1996).

A maior hierarquia fluvial da área de pesquisa é de $6^{\circ}$ ordem, representada pelo Rio Novo. Os rios Ponte Alta, Rio das Balsas e do Rio Manoel Alves da Natividade possuem $5^{\circ}$ ordem; os Rios Sapão e Rio Vermelho possuem $4^{\circ}$ ordem; do Córrego Grande possui $3^{\circ}$ ordem e a do Rio do Santo que possui $2^{\circ}$ ordem (Figura 3 ).

De maneira geral, a direção da rede de drenagem predominante, na área de pesquisa, está representada, na porção leste, por uma direção dos canais de escoamento de sudeste (SE) a noroeste (NO) e na porção oeste uma direção dos canais de escoamento de nordeste (NE) para sudoeste (SO).

\section{Magnitude e comprimento total}

Observa-se que a magnitude total dos canais de drenagem na área de pesquisa é de 1.473 canais de escoamento de $1^{a}$ ordem, sendo que as sub-bacias hidrográficas de maior magnitude são a do Rio Novo que possui 828 canais de escoamento e do Rio Manoel Alves da Natividade 136 canais de escoamento. A menor magnitude é encontrada no rio Santo com 8 canais de escoamento.

A alta concentração de canais fluviais de $1^{a}$ ordem na sub-bacia hidrográfica do Rio Novo, conforme Christofolletti (1974) pode indicar uma forte condição de esculturação do relevo pela ação de processos erosivos.

Geografia Ensino \& Pesquisa, v. 18, n.3, p. 103-116, set./dez. 2014.

Cristo, S. S. V. de;

Robaina, L. E. de S. 


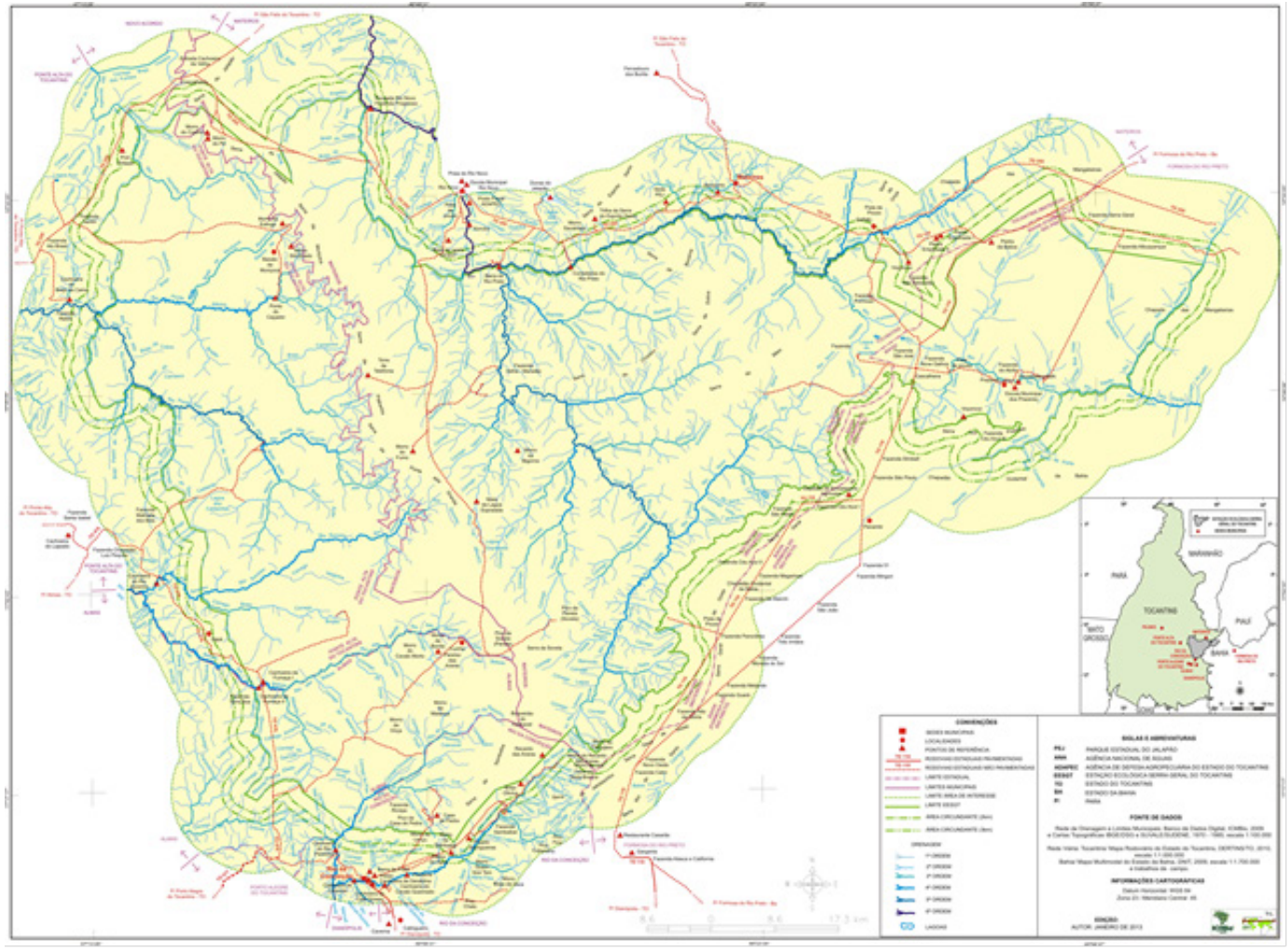

Fonte: elaborado pelos autores.

O comprimento total dos cursos fluviais da área de pesquisa é de 5.369,4km, sendo que a sub-bacia hidrográfica do Rio Novo é de 2.747,2km e do Rio Ponte Alta com 771,7km. O menor comprimento total encontra-se no Rio do Santo com 14,2km.

\section{Magnitude e comprimento total}

Observa-se que a magnitude total dos canais de drenagem na área de pesquisa é de 1.473 canais de escoamento de $1^{a}$ ordem, sendo que as sub-bacias hidrográficas de maior magnitude são a do Rio Novo que possui 828 canais de escoamento e do Rio Manoel Alves da Natividade 136 canais de escoamento. A menor magnitude é encontrada no rio Santo com 8 canais de escoamento.

A alta concentração de canais fluviais de $1^{a}$ ordem na sub-bacia hidrográfica do Rio Novo, conforme Christofolletti (1974) pode indicar uma forte condição de esculturação do relevo pela ação de processos erosivos.

O comprimento total dos cursos fluviais da área de pesquisa é de $5.369,4 \mathrm{~km}$, sendo que a sub-bacia hidrográfica do Rio Novo é de $2.747,2 \mathrm{~km}$ e do Rio Ponte Alta com $771,7 \mathrm{~km}$. O menor comprimento total encontra-se no Rio do Santo com 14,2km.

Geografia Ensino \& Pesquisa, v. 18, n.3, p. 103-116, set./dez. 2014.

Caracterização da rede hidrográfica na Estação Ecológica Serra Geral do Tocantins, Estados do Tocantins e Bahia

\section{Densidade de drenagem}

A densidade de drenagem total da área de pesquisa é de $0,43 \mathrm{~km} / \mathrm{Km}^{2}$, sendo que as sub-bacias hidrográficas que apresentam as maiores densidades de drenagens são: as do Córrego Grande 
$\left(0,73 \mathrm{~km} / \mathrm{Km}^{2}\right)$, do Rio Novo $\left(0,53 \mathrm{~km} / \mathrm{Km}^{2}\right)$ e do Rio Manoel Alves da Natividade $\left(0,53 \mathrm{~km} / \mathrm{Km}^{2}\right)$, sendo estas que possuem maior grau de dissecação topográfica pela atuação dos cursos fluviais.

Segundo Junior \& Rossete (2005) a densidade de drenagem ou a relação existente entre o comprimento total dos canais e a área da bacia, parâmetros definidos por Horton (1945), refletem o grau de dissecação topográfica em paisagens elaboradas pela atuação fluvial, expressando em última análise, a quantidade disponível de canais de escoamento.

O comportamento hidrológico das rochas e dos regolitos, em um mesmo ambiente climático, vai repercutir na densidade de drenagem, sendo que nas rochas e regolitos, onde a infiltração é mais dificultada há maior escoamento superficial, gerando possibilidades maiores para esculturação de canais permanentes e consecutiva densidade de drenagem mais elevada (CHRISTOFOLETTI, 1969).

Ainda conforme o mesmo autor citando RAY (1963) as rochas sedimentares, clásticas de granulação fina geralmente apresentam drenagem de texturas finas (existência de espaçamentos estreitos entre os cursos de água) enquanto que as rochas sedimentares de granulometria grossa, como os arenitos, tendem a apresentar textura grosseira ou baixa (existência de espaçamentos amplos entre os cursos de água).

Em síntese, os valores baixos de densidade de drenagem refletem a característica geral da área de estudo que está representada por um relevo predominantemente suave com condições de alta permeabilidade devido ao predomínio de litologias arenosas com um bom grau de infiltração de água no solo.

\section{Padrões de drenagem}

Os padrões de drenagem referem-se ao arranjo espacial dos cursos fluviais, que podem ser influenciados em sua atividade morfogenética pela natureza e disposição das camadas rochosas, pela resistência litológica variável, pelas diferenças de declividade e pela evolução geomorfológica da região. Sendo que uma ou mais bacias de drenagem podem estar englobadas na caracterização de determinado padrão.

A sub-bacia hidrográfica do Rio Novo, Rio Vermelho, Rio do Santo e Córrego Grande apresentam padrão dendrítico-retangular, onde à rede de drenagem se distribui em várias direções, com a presença de anomalias pela existência de confluências em ângulos retos, junto as suas áreas de cabeceiras, demonstrando um controle estrutural da rede de drenagem (Figura 4).

Segundo Christofoletti (1974) o padrão dendrítico é tipicamente desenvolvido sobre rochas de resistência uniforme, ou em estruturas sedimentares horizontalizadas. Características últimas que se assemelham aos aspectos geológicos observados na área de pesquisa.

A sub-bacia hidrográfica do Rio Sapão apresenta padrões treliça e retangular, sendo que o padrão treliça se caracteriza pelos canais de drenagem principais que correm paralelos recebendo afluentes que fluem em direções transversais a estes, formando ângulos retos e o padrão retangular, que se caracteriza pelas bruscas alterações retangulares nos cursos fluviais. Ambos os padrões de drenagem, demonstram um forte controle estrutural sobre a rede de drenagem da sub-bacia.

Segundo Christofoletti (1974) a drenagem em treliça é composta por rios principais consequentes, correndo paralelamente, recebendo afluentes subsequentes que fluem em direção transversal aos primeiros, os rios subsequentes, por sua vez, recebem rios obsequentes e resequentes. Sendo que geralmente, as confluências realizam-se em ângulos retos.

O controle estrutural sobre este padrão é muito acentuado devido a desigual resistência das camadas inclinadas, aflorando em faixas estreitas e paralelas, e o entalhe dos tributários subsequentes sobre as rochas mais frágeis promove a formação de cristas paralelas, por causa das camadas mais resistentes, acompanhadas de vales subsequentes nas rochas mais brandas.

Geografia Ensino \& Pesquisa, v. 18, n.3, p. 103-116, set./dez. 2014.

Cristo, S. S. V. de;

Robaina, L. E. de S. 
Figura 4- Padrões de drenagem da área de pesquisa

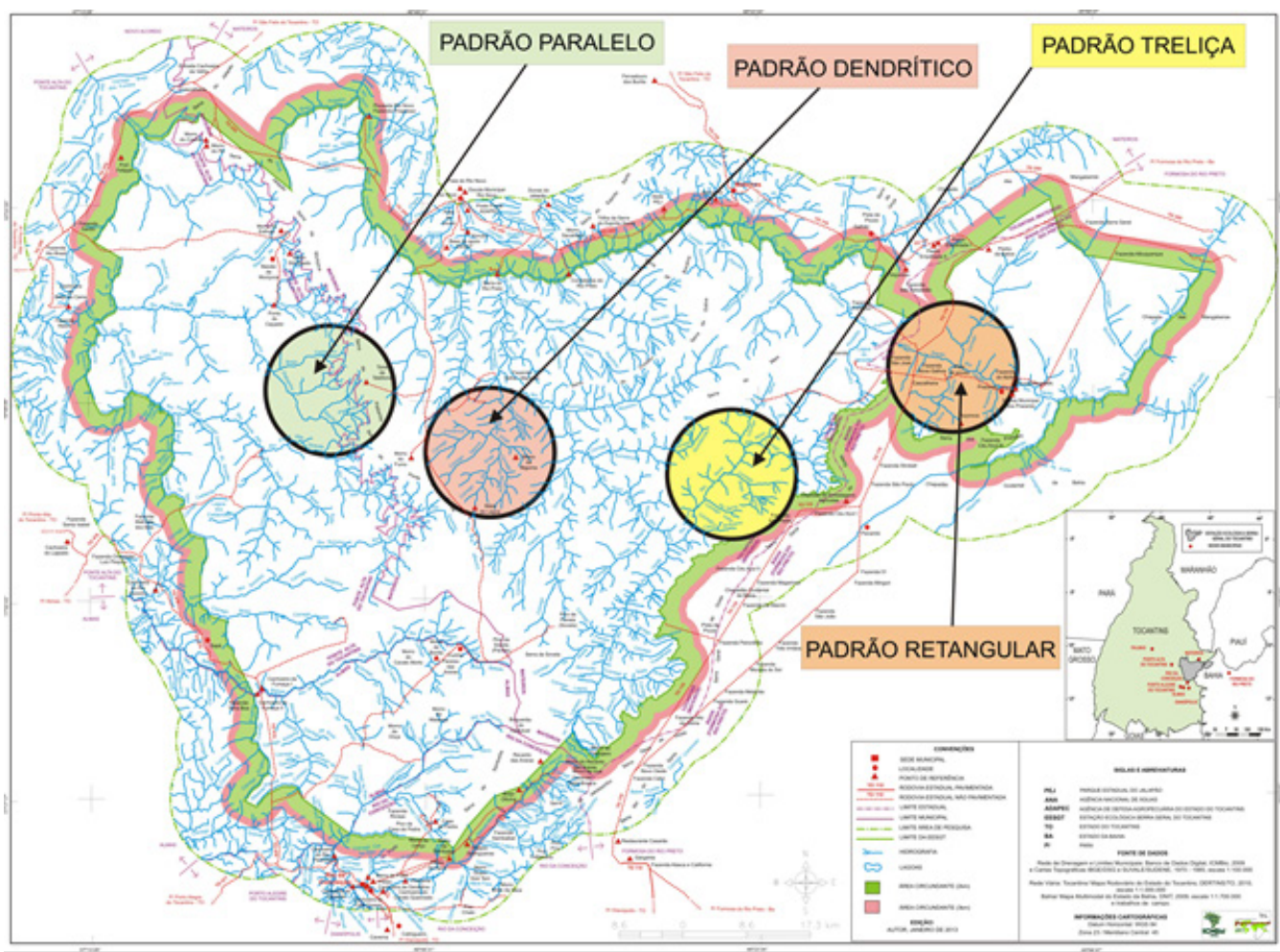

Fonte: elaborado pelos autores.

Já as sub-bacias hidrográfcas dos Rios Ponte Alta, das Balsas e Manoel Alves da Natividade, apresentam um padrão paralelo onde os cursos fluviais sucessivos escoam quase que paralelamente uns aos outros. Esse padrão conforme Christofoletti (1974) pode estar associado a áreas onde há presença de vertentes com declividades acentuadas ou onde existem controles estruturais, que motivam a ocorrência de espaçamento regular, quase paralelo, dos cursos fluviais. Na área, observa-se a predominância deste padrão, nas drenagens junto à escarpa de dissecação que formam uma faixa NW-SE.

Uma síntese dos aspectos morfométricos das bacias hidrográficas que integram a área de pesquisa pode ser verificada com base na observação do quadro 1.

Geografia Ensino \& Pesquisa, v. 18, n.3, p. 103-116, set./dez. 2014.

Caracterização da rede hidrográfica na Estação Ecológica Serra Geral do Tocantins, Estados do Tocantins e Bahia

\section{Cachoeiras e Corredeiras}

As cachoeiras são feições geomorfológicas caracterizadas pela presença de desníveis existente nos leitos das drenagens, originando significativas quedas de água que se distribuem na área de pesquisa.

A principal causa da formação das cachoeiras, na região, são falhamentos que seccionam o curso do rio e a erosão diferencial que atuam sobre o embasamento geológico. Representam um forte controle estrutural da geologia local que proporciona a perda de continuidade das camadas de rochas formadoras do embasamento do leito dos rios. Embasamento que, também, é afetado por erosão diferencial das rochas com diferentes resistências. Entre estas feições destacam-se as cachoeiras da Fumaça (Figura 5A), do Rio Soninho (Figura 5B) e do Brejo da Cama (Figura 5C). 
Quadro 1 - Características morfométricas das sub-bacias hidrográficas da área de pesquisa

\begin{tabular}{|c|c|c|c|c|c|c|c|}
\hline $\begin{array}{l}\text { Sub-bacias } \\
\text { hidrográficas }\end{array}$ & Área $\left(\mathrm{km}^{2}\right)$ & $\begin{array}{l}\text { Hierarquia } \\
\text { Fluvial }\end{array}$ & $\begin{array}{c}\text { Magnitude } \\
\text { Total (canais } \\
\text { de } 1^{\text {a ordem) }}\end{array}$ & $\begin{array}{c}\text { Densidade de } \\
\text { drenagem total } \\
\left(\mathbf{k m} / \mathrm{km}^{2}\right)\end{array}$ & $\begin{array}{l}\text { Comprimento } \\
\text { Total (km) }\end{array}$ & $\begin{array}{c}\text { Sentido } \\
\text { principal da } \\
\text { drenagem }\end{array}$ & $\begin{array}{l}\text { Padrão de } \\
\text { drenagem }\end{array}$ \\
\hline Rio Novo & $5.168,5$ & 60 ordem & 828 & 0,53 & $2.747,2$ & (SE) a (NO) & Dendrítico \\
\hline Rio Sapão & $1.949,2$ & 4 o ordem & 80 & 0,20 & 401,5 & $(\mathrm{O})$ a (L) & Treliça \\
\hline Rio Ponte Alta & $1.744,6$ & 5o ordem & 180 & 0,44 & 771,7 & (L) a (O) & Paralelo \\
\hline Rio das Balsas & $1.579,4$ & 5o ordem & 165 & 0,44 & 704,2 & (NE) a (SO) & Paralelo \\
\hline $\begin{array}{c}\text { Rio Manoel Alves } \\
\text { da Natividade }\end{array}$ & 877,2 & 5o ordem & 136 & 0,53 & 469,7 & (NE) a (SO) & Paralelo \\
\hline Rio Vermelho & 635,8 & 40 ordem & 39 & 0,17 & 109,4 & (SE) a (NO) & Dendrítico \\
\hline Rio do Santo & 216,8 & 20 ordem & 8 & 0,06 & 14,2 & (NO) a (SE) & Dentrítico \\
\hline Córrego Grande & 205,7 & 3o ordem & 37 & 0,73 & 151,5 & (NE) a (SO) & Dentrítico \\
\hline Total & $12.377,1$ & & 1.473 & 0,43 & 5369,4 & & \\
\hline
\end{tabular}

Fonte: elaborado pelos autores.

Figura 5 - Cachoeiras da área de pesquisa: da Fumaça (A), do Rio Soninho (B) e do Brejo da Cama (C).

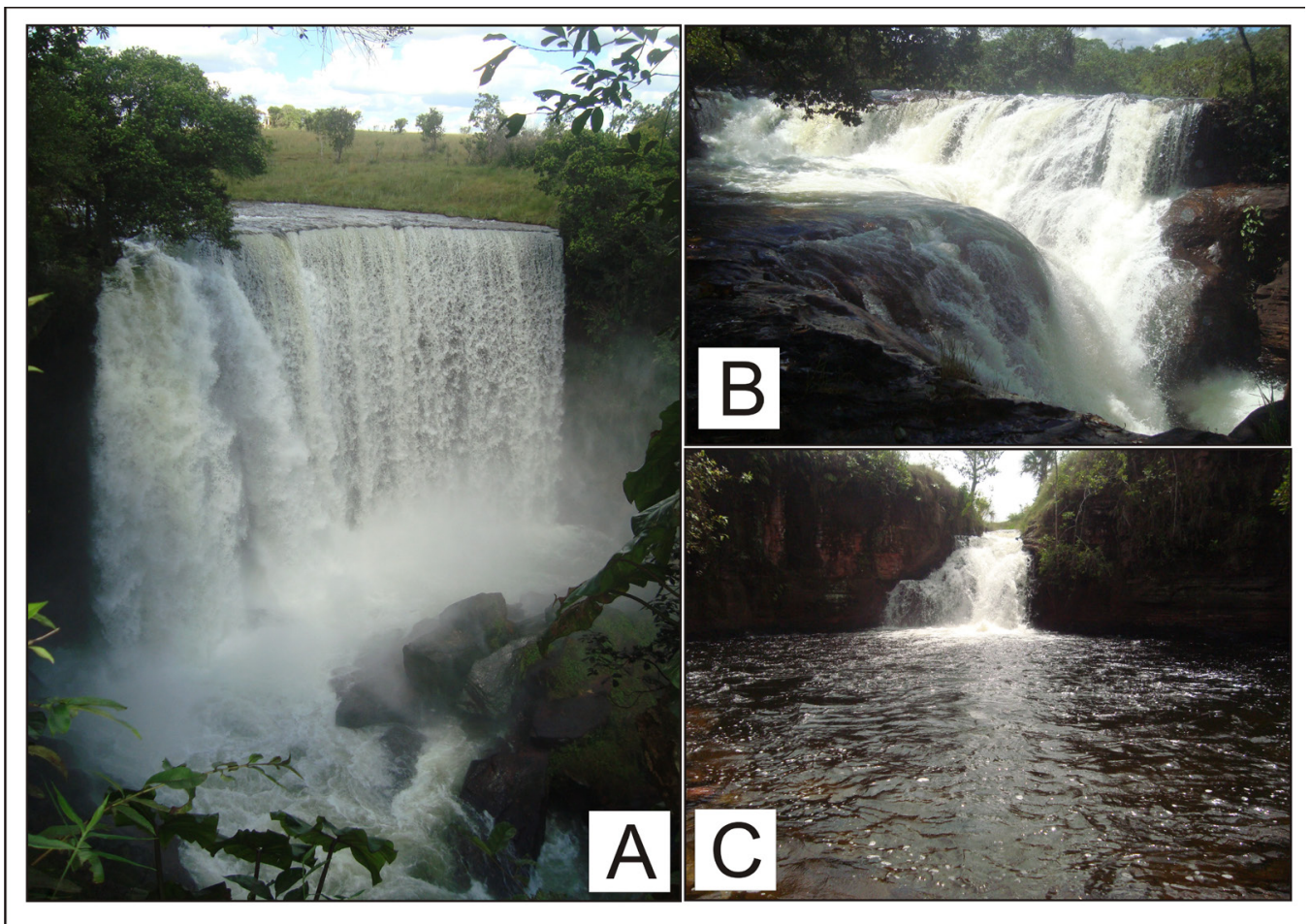

Fonte: autor, novembro de 2010.

As Corredeiras são feições geomorfológicas marcadas pela presença de pequenos desníveis de camadas rochosas existentes no leito das drenagens locais originando rápidas quedas de água que se distribuem na área de pesquisa.

A origem destas feições se associa, principalmente, à erosão remontante de antigas quedas de água que foram reduzidas em tamanho por desgaste natural feito pela água com o passar do tempo.

As mesmas são formadas pelas condições das drenagens que se apresentam sob um forte controle estrutural feito pela geologia local, somado ao significativo volume de água, à alta velocidade de fluxo e a um alto poder erosivo que escava o embasamento rochoso. Entre essas feições podem ser destacadas as Corredeiras dos Rios Manoel Alves (Figura 6A), das Balsas (Figura 6B) e Novo (Figura 6C).

Geografia Ensino \& Pesquisa, v. 18, n.3, p. 103-116, set./dez. 2014.

Cristo, S. S. V. de;

Robaina, L. E. de S.

ISSN 2236-4994 


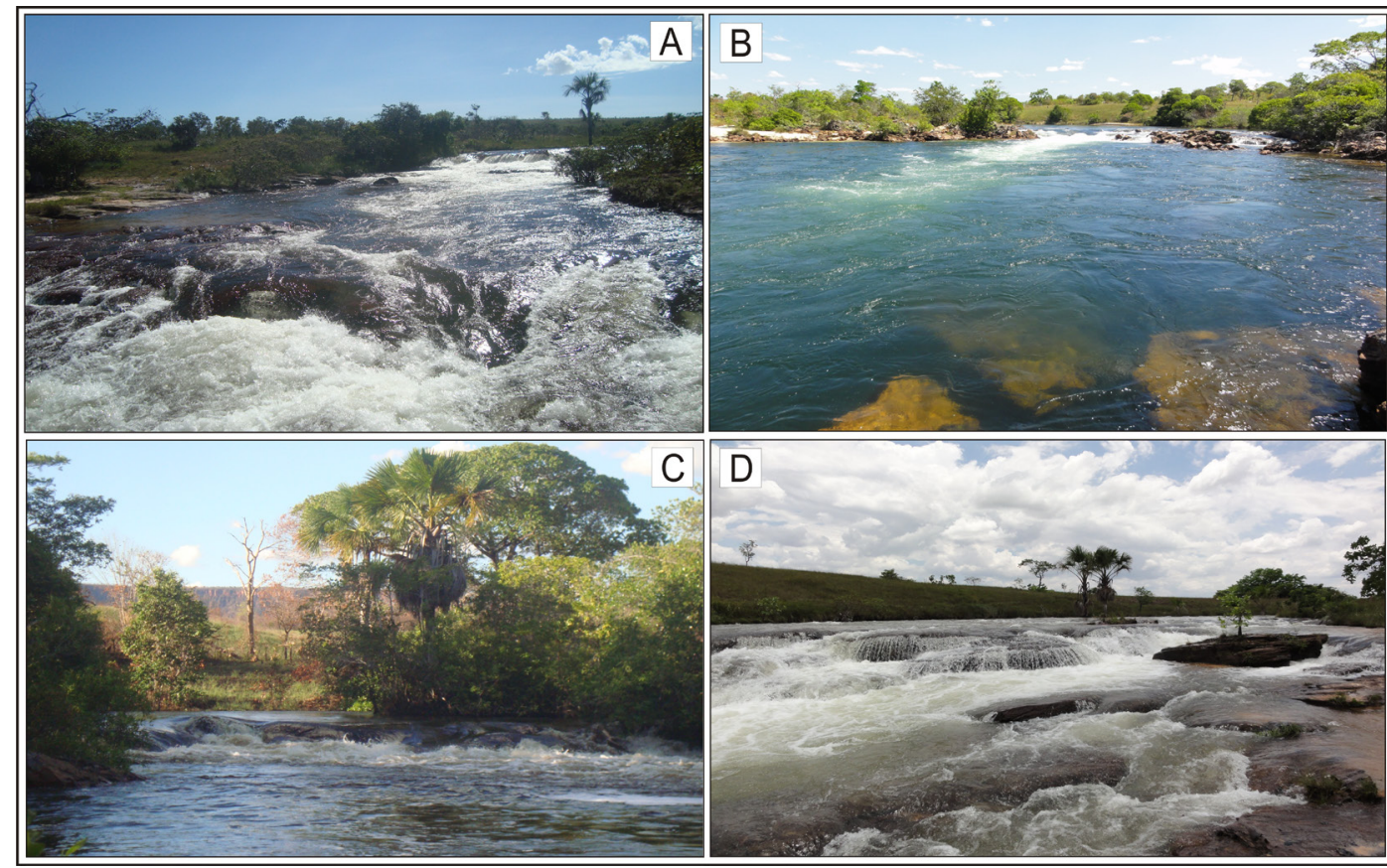

Fonte: autor, novembro de 2010.

\section{Veredas e lagoas}

Resolução CONAMA $\mathrm{N}^{\mathrm{o}}$ 004, de 18 de setembro de 1985. Disponível em $<$ http://www.cetesb.sp.gov. br/legislacao/1985_Res_ CONAMA_4.pdf $>$. Acesso em 14 mar. 2011 as 09:30 horas.

Geografia Ensino \& Pesquisa, v. 18, n.3, p. 103-116, set./dez. 2014

Caracterização da rede hidrográfica na Estação Ecológica Serra Geral do Tocantins, Estados do Tocantins e Bahia
O termo "vereda" é um nome dado no Brasil Central para caracterizar todo espaço brejoso ou encharcado que contêm nascentes ou cabeceiras de cursos d'água de rede de drenagem, onde há ocorrência de solos hidromórficos com renques de buritis e outras formas de vegetação típica (Conselho Nacional de Meio Ambiente - CONAMA, 1985)².

$\mathrm{Na}$ área de pesquisa, ocorre em vales rasos com concentração de água em superfície, que estão interligadas a rede de drenagem, auxiliando na manutenção e escoamento da água dos canais fluviais que fazem a esculturação do relevo (Figura 7).

Segundo Augustin et al,. (2009), as veredas podem ser consideradas feições geomorfológicas, porque somente ocorrem ao longo de vales pouco profundos, com baixa energia hidráulica e alcançam dezenas de quilômetros, interligadas aos sistemas de drenagem regionais do centro e de parte do sudeste brasileiro.

Destaque-se que as queimadas afetam diretamente a vegetação das veredas, como se pode constatar pelas cicatrizes deixadas nos troncos e galhos da vegetação de porte arbóreo como os buritis e demais exemplares vegetais que tem seu desenvolvimento prejudicado, bem como das raízes, principalmente pela queima da matéria orgânica em profundidade no solo, provocando a morte de alguns vegetais e também o colapso do solo com o rebaixamento do mesmo e perda de matéria orgânica ocasionando sua infertilidade.

O pisoteio do gado, devido à utilização das veredas como locais de pastagens, em períodos secos, somado a retirada da cobertura vegetal natural, como a coleta do capim dourado, muito utilizado para fins comerciais, também promove alteração das veredas.

A ocorrência das veredas condiciona-se ao afloramento do lençol freático, exercendo papel fundamental na manutenção do sistema hidrológico, uma vez que as áreas úmidas do Cerrado funcionam como "esponjas ou filtros naturais" para os cursos d'água (MEIRELLES et al,. 2006). 
Figura 7 - Aspectos de veredas observadas na área de pesquisa.

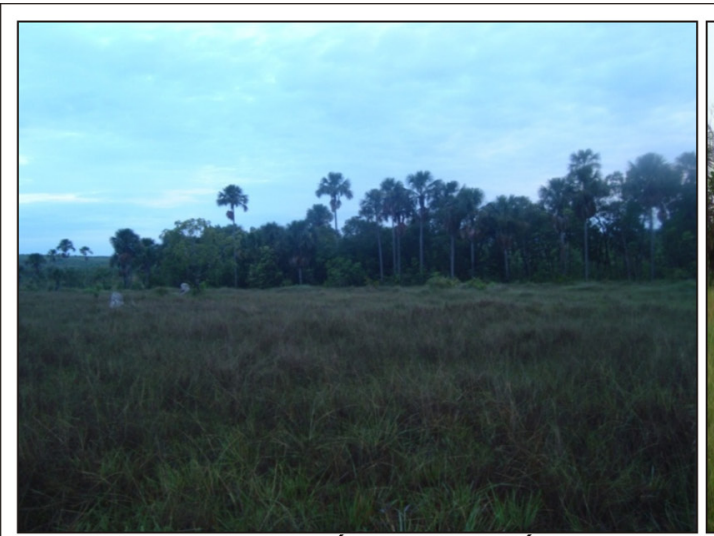

VEREDA DO CÓRREGO CASCÁVEL

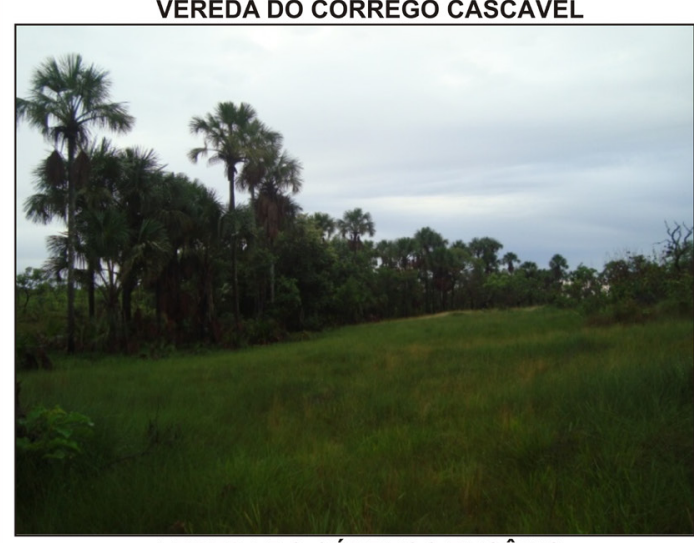

VEREDA DO CÓRREGO EUGÊNIO

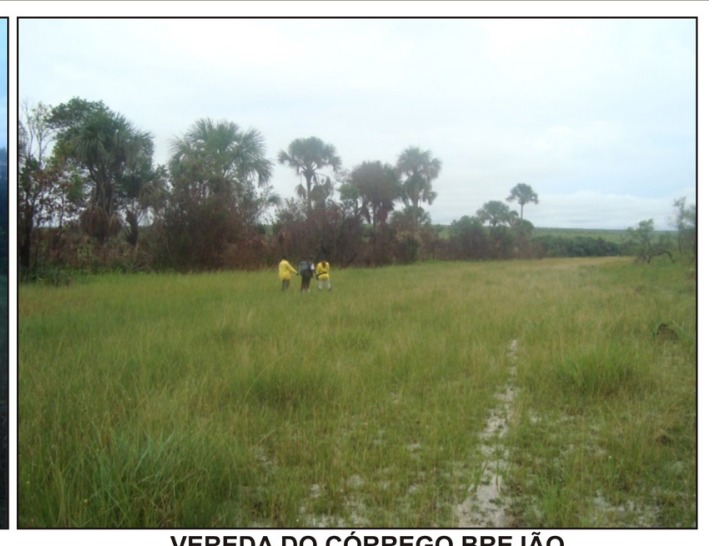

VEREDA DO CÓRREGO BREJÃO

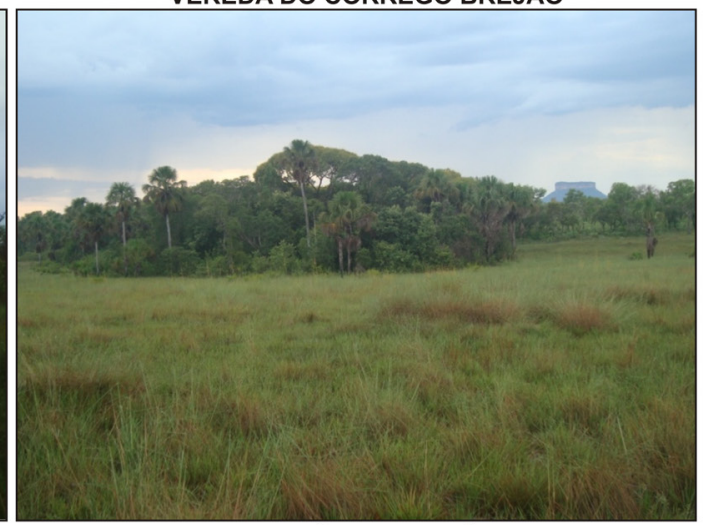

VEREDA DO CÓRREGO JOÃO PRETO

Fonte: autor, janeiro de 2010 .

Em síntese, as observações feitas quanto às características físicas e a degradação ambiental das veredas, demonstram que, apesar de sua fundamental importância, estas não estão sendo respeitadas, ainda que representem as principais fontes de água que armazenam e abastecem os cursos fluviais da área de pesquisa.

As lagoas, assim como as veredas, também estão relacionadas diretamente a rede drenagem local, uma vez que representam áreas de surgência de água em superfície, formadas pelo afloramento do lençol freático em áreas rebaixadas que ocupam áreas de planície aluvial. Desta forma, também auxiliam no armazenamento e abastecimento gradual dos cursos fluviais locais, uma vez que concentram água em períodos chuvosos, quando aumentam seu tamanho e profundidade, permitindo a continuidade de escoamentos em períodos secos, reduzindo de tamanho com possibilidade de secarem.

Segundo Guerra (1993) lagoa é uma depressão de formas variadas, principalmente tendendo a circulares, com profundidades pequenas e cheia de água doce ou salgada. Geralmente são alimentados por um ou mais rios afluentes e rios emissários o que evita seu transbordamento.

$\mathrm{Na}$ área de estudo, três lagoas são características: Lagoas das Dunas, localizada no município de Mateiros (TO), Lagoa Bonita, localiza-se no município de Rio da Conceição (TO) e a lagoa dos Caldeirões, localizada no município de Ponte Alta do Tocantins (TO) (Figura 8).

Assim como as áreas de veredas, as lagoas da área de pesquisa sofrem com a degradação ambiental ocasionada principalmente pela ação das queimadas que eliminam a cobertura vegetal das áreas marginais deixando o solo exposto aos processos erosivos que favorecem o transporte de sedimentos para o interior das lagoas assoreando-as e diminuindo sua capacidade de retenção e armazenamento de água (Figuras 9A e 9B).

Geografia Ensino \& Pesquisa, v. 18, n.3, p. 103-116, set./dez. 2014.

Cristo, S. S. V. de;

Robaina, L. E. de S.

ISSN 2236-4994 
Figura 8-Aspectos das principais Lagoas encontradas na área de pesquisa.

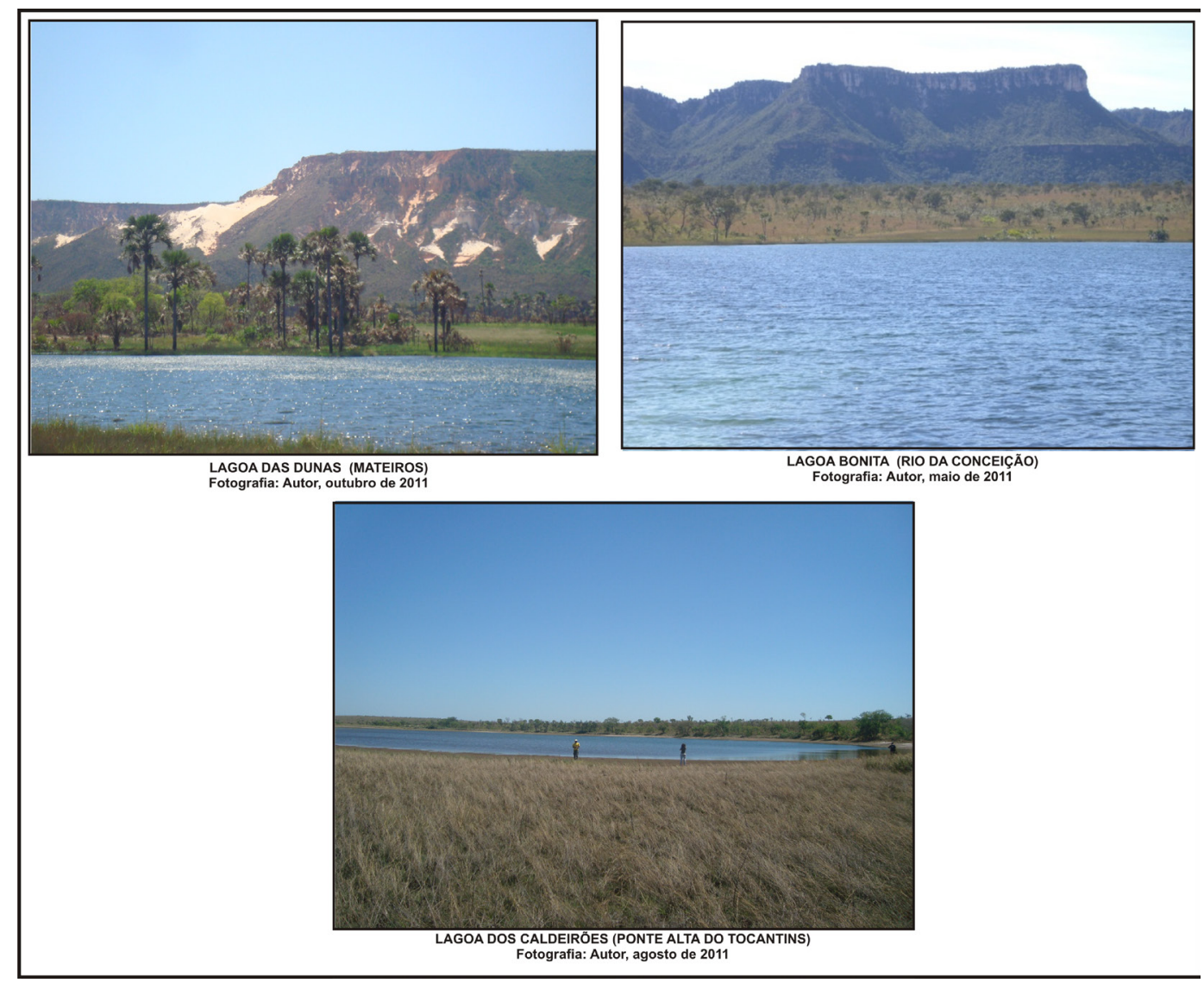

Fonte: autor, janeiro de 2010.

Figura 9 - A- Visualização do impacto ocasionado por queimadas na margem (A) e interior (B) da Lagoa dos Caldeirões (Ponte Alta do Tocantins).

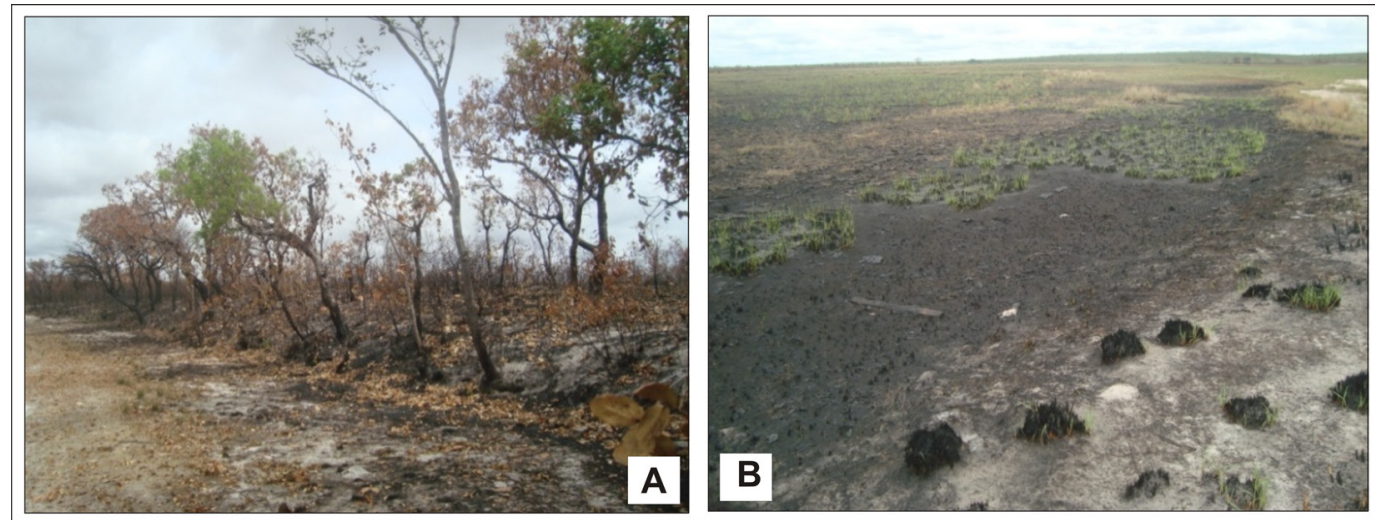

Fonte: autor, outubro de 2011.

Geografia Ensino \& Pesquisa, v. 18, n.3, p. 103-116, set./dez. 2014.

Caracterização da rede hidrográfica na Estação Ecológica Serra Geral do Tocantins, Estados do Tocantins e Bahia

114 I ISSN 2236-4994
Além das queimadas, alguns impactos favorecem o assoreamento das lagoas, a saber, a abertura de vias rodoviárias que eliminam a vegetação expondo o solo e facilitando o transporte de sedimentos para seu interior.

Considera-se que a origem destas feições, veredas e lagoas, está relacionada a exposição do aqǘffero presente nas rochas permeáveis da área de estudo, muitas vezes condicionados a estruturas geológicas (Figura 10). 
Figura 10 - Representação esquemática da formação de lagoas e veredas na área de pesquisa.

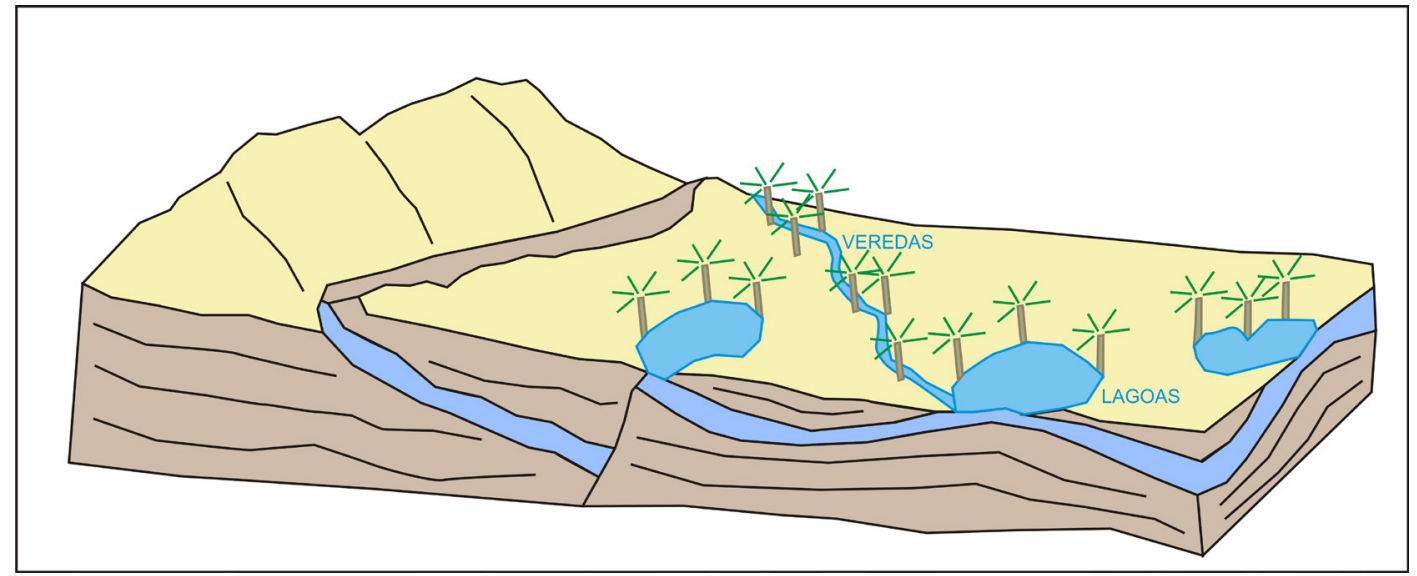

Fonte: elaborado pelos autores.

\section{Considerações finais}

A hidrografia mostra-se não apenas fundamental na manutenção e na distribuição da fauna e da flora local, mas também na representação da importância da área de estudo, principalmente devido à existência de ampla e densa rede de canais fluviais com abundância de água doce, de nascentes de drenagens locais, regionais e nacionais como dos Rios Tocantins-Araguaia e São Francisco que integram o conjunto das principais bacias hidrográficas do país.

Quanto aos aspectos morfométricos da área de pesquisa destaca-se que a maior hierarquia fluvial é de $6^{\circ}$ ordem, representada pelo Rio Novo; a direção da rede de drenagem predominante está representada, na porção leste, por uma direção dos canais de sudeste a noroeste e na porção oeste uma direção dos canais de nordeste para sudoeste; a magnitude total é de 1.473 canais de escoamento de $1^{\mathrm{a}}$ ordem. A densidade de drenagem total é de $0,43 \mathrm{~km} / \mathrm{Km}^{2}$, sendo que as sub-bacias hidrográficas que apresentam a maior densidade é a do Córrego Grande $(0,73 \mathrm{~km} / \mathrm{Km})$. Os padrões de drenagem predominantes são retangular, os quais demonstram de modo geral um forte controle estrutural da geologia local sobre a rede de drenagem.

Ainda são significativas as feições de cachoeiras e corredeiras, encontradas principalmente nos rios das Balsas, do Manoel Alves, Preto e Novo.

As veredas e lagoas servem como locais de armazenamento e reguladores naturais das águas fluviais que abastecem os Estados do Tocantins e da Bahia, entretanto têm sido degradadas pela ação antrópica.

De maneira conclusiva a hidrografia mostra-se não apenas como elemento de primordial importância para a EESGT, mas também como elemento imprescindível na preservação ambiental do Cerrado e da vida como um todo, tanto dos animais, como dos vegetais e principalmente dos seres humanos que fazem seu uso de forma direta ou indiretamente.

\section{Referências}


União da Geomorfologia Brasileira, v.10, n 1, 2009. p.103-114.

BRASIL. Lei no 9.985. Brasília: 18 de julho de 2000. Disponível em: < http:/ /www.planalto.gov.br/ccivil_03/Leis/L9985.htm>. Acesso em: 24 fev. 2011

BRASIL. Resolução CONAMA n ${ }^{\mathbf{0}}$ 13, de 6 de dezembro de 1990. Disponível em: <http:/ /www.mma. gov.br/port/conama/legiabre.cfm?codlegi=110>. Acesso em: 24 fev. 2011.

CHRISTOFOLETTI, A. Análise morfométrica de bacias hidrográficas. Campinas - SP: Notícia Geomorfológica, 9 (18), 1969, p. 35-64.

CHRISTOFOLETTI, A. Geomorfologia Fluvial. São Paulo - SP: Edgard Blücher, 1980.

CHRISTOFOLETTI, A. Geomorfologia. São Paulo - SP: Edgard Blücher/ EDUSP, 1974.

CUNHA, S.B.; GUERRA, A. J. T. Geomorfologia e meio ambiente. Rio de Janeiro - RJ: Bertrand Brasil, 1996.

GUERRA, A. J. T. Dicionário Geológico Geomorfológico. Rio de Janeiro - RJ: 1ª ed., IBGE, 1993. 446p

MEIRELLES, M. L.; FERREIRA, A.B.; \& FRANCO, A.C. Dinâmica sazonal do carbono em campo úmido do Cerrado. Planaltina - DF: Embrapa Cerrados, 2006. 32 p. Ministério do Meio Ambiente. Disponível em: <http://www.mma.gov.br/sitio>. Acesso em: 24 abr. 2012.

MILANI, J. R. \& CANALI, N. E. O Sistema Hidrográfico do Rio Matinhos: uma análise morfométrica. Curitiba - PR: R. RA'EGA, Editora da UFPR, n. 4, 2000.

MYERS, N. R. A. et al,. Biodiversity hotspots for conservation priorities. Nature, 403, 2000.

SEPLAN. Atlas do Tocantins: Subsídios ao Planejamento da Gestão Territorial. Palmas - TO: Secretaria do Planejamento e da Modernização Pública - SEPLAN, Superintendência de Pesquisa e Zoneamento Ecológico-Econômico, Diretoria de Zoneamento Ecológico-Econômico - DZE, 6 ed. 2012. 80 pag.

\section{Correspondência}

\section{Sandro Sidnei Vargas de Cristo}

E-mail: sidneicristo@mail.uft.edu.br

Recebido em 7 de julho de 2014.

Aceito para publicação em 11 de dezembro de 2014. 